\section{Intensity scales for pure tastes and for taste mixtures}

\author{
HOWARD R. MOSKOWITZ* \\ U.S. Army Natick Laboratories, Natick, Massachuse tts 01760
}

In four series of studies, taste intensities of sour, bitter, sweet, and salt were measured by number matching (magnitude estimation), and by noise matching. The two procedures agreed in their estimates of the power-function exponent for each taste. Representative exponents obtained from the studies are 1.0 to 1.1 for sour and bitter and 1.3 to 1.5 for sweet and salt. In a second set of studies each taste was judged against three or more background levels of a second taste. The results suggest that the power-function exponen 1 is unaffected when a second taste is present in the solution. Whether the intercept changes in taste mixtures was not determined in these experiments.

During the past 17 years numerous studies have repeatedly shown that the apparent perceptual intensity of stimuli $S$ grows as a power function of the physical intensity I (Stevens, 1960, 1966a). This result ties together different sensory systems and is expressed by the simple psychophysical equation $S=k I^{n}$, or $\log S=$ $n \log l+\log k$. The exponent $n$ governs the rate at which sensory intensity grows with physical intensity, and it has the property of being independent of both the position of the stimuli on the physical scalc and of the $\mathrm{O}^{\prime}$ s choice of modulus (scale unit). Brightness and loudness were the two modalities of the initial inquiry in to the dynamics of sensory intensity (Stevens, 1953). In each, the simple power relation fits the growth function remarkably well across practically the entire sensory range. The exponent for each is below 1.0. about 0.33 for brightness (against luminous energy: Stevens \& Stevens, 1960), and about 0.64 to 0.67 for loudness (against sound pressure; Stevens, 1966a, 1969a). Because each exponent is below 1.0 . brightness and loudness grow as decelerating functions of physical intensity.

A similar analysis may be made for the sensory dynamics of taste intensity. The published results of such investigations do not converge on a single estimate for the exponent of taste, but rather each taste modality (salt, sour, sweet, and bitter) appears to be governed by a different exponent (Ekman \& Ákesson. 1964; Meiselman, 1968; Stevens, 1969b). Within a single modality different substances such as sucrose, cyclamate, and saccharin, which

*l:S. A rmy Natick I aboratorics. Natick, Man, 01760. Supported in part by a National Science loundation predoctoral fellow ship and in part by NIH Grant NB 02974 llaboratory of Psychophysics Report PlR 359). The results were reported in a doctoral disertation submitted to Harvard University. 1968. gives the higher estimate, often two to all taste sweet, are governed by different sweetness exponents (Moskowitz, 1970a, b). Various procedures of administering the stimulus, such as letting it flow over the tongue or sipping it from cups, also give different estimates of the exponent. The sipping procedure typically three times higher than the flowing procedure (McBurney, 1965; Stevens, 1969b; Meiselman ${ }^{1}$ ). Finally, even with a single procedure, sipping, difteren 1 Es have oblained very different estimates of the exponent for sucrose swectness, ranging from a low around 0.5 (Kocher \& Fisher, 1969) to a high around 1.5 to 1.6 (Ekman \& Akesson, 1964; Moskowit $2,1970 \mathrm{a}, \mathrm{b}$ ).

Mixtures of different lastes have also been explored. Several Es report that tastes usually suppress each other (Pangborn. 1960, 1961, 1962; Kamen et al, 1962; Pfaffmann et al, in press), although enhancement of sweetness has sometimes been reported when slight amounts of

\begin{tabular}{|c|c|c|c|c|c|c|c|c|}
\hline 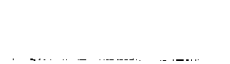 & & Sti & ulus $C$ & $\begin{array}{l}\text { I } \\
\text { centratio }\end{array}$ & & & & \\
\hline Experiment & 1 & 2 & 3 & 4 & 5 & 6 & 7 & 8 \\
\hline $\begin{array}{l}\text { Sour } \\
\text { lixperiment } 1 \\
\text { Ixperiments } 2 \text { and } 3 \\
\text { Interactions }\end{array}$ & 0.02 & $\begin{array}{l}0.04 \\
0.04 \\
0.04\end{array}$ & $\begin{array}{l}0.08 \\
0.08 \\
0.08\end{array}$ & $\begin{array}{l}0.15 \\
0.15 \\
0.15\end{array}$ & $\begin{array}{l}0.30 \\
0.30 \\
0.30\end{array}$ & $\begin{array}{l}0.60 \\
0.60 \\
0.60\end{array}$ & $\begin{array}{l}1.20 \\
1.20 \\
1.20\end{array}$ & 2.40 \\
\hline \begin{tabular}{l}
\multicolumn{1}{c}{ Bitter } \\
Experiment 1 \\
Experiment 2 \\
Interactions
\end{tabular} & 0.001 & 0.002 & $\begin{array}{l}0.004 \\
0.004 \\
0.004\end{array}$ & $\begin{array}{l}0.008 \\
0.008 \\
0.008\end{array}$ & $\begin{array}{l}0.015 \\
0.015 \\
0.015\end{array}$ & $\begin{array}{l}0.030 \\
0.030 \\
0.030\end{array}$ & $\begin{array}{l}0.060 \\
0.060 \\
0.060\end{array}$ & $\begin{array}{l}0.120 \\
0.120 \\
0.120\end{array}$ \\
\hline $\begin{array}{l}\text { Sweet } \\
\text { 1. vperiment ] } \\
\text { [xperinent } 2 \\
\text { Laperiment } 3 \\
\text { interactions }\end{array}$ & $\begin{array}{r}1.90 \\
1.63 \\
19.35 \\
2.00\end{array}$ & $\begin{array}{r}3.10 \\
2.72 \\
26.47 \\
4.00\end{array}$ & $\begin{array}{r}5.20 \\
4.40 \\
35.06 \\
8.00\end{array}$ & $\begin{array}{r}8.70 \\
7.06 \\
45.20 \\
15.00\end{array}$ & $\begin{array}{l}14.50 \\
11.19 \\
55.55 \\
30.00\end{array}$ & $\begin{array}{l}24.00 \\
17.29 \\
65.75 \\
60.00\end{array}$ & 40.00 & 64.00 \\
\hline $\begin{array}{l}\quad \text { Salt } \\
\text { 1.xperiments } 1 \text { and } 2 \\
\text { Lxperiment } 3 \\
\text { lixperiments } 4 \text { and } 5 \\
\text { laperiment } 6 \\
\text { Interaction I } \\
\text { Interaction } 2\end{array}$ & $\begin{array}{l}0.70 \\
1.00 \\
0.99 \\
0.99 \\
1.00 \\
0.99\end{array}$ & $\begin{array}{l}1.10 \\
1.75 \\
1.96 \\
1.96 \\
1.75 \\
1.96\end{array}$ & $\begin{array}{l}1.90 \\
3.00 \\
3.85 \\
3.85 \\
3.00 \\
3.85\end{array}$ & $\begin{array}{l}3.10 \\
5.50 \\
7.40 \\
7.00 \\
5.50 \\
7.00\end{array}$ & $\begin{array}{r}5.20 \\
9.50 \\
13.80 \\
13.04 \\
9.50 \\
13.04\end{array}$ & $\begin{array}{r}8.60 \\
16.00 \\
24.24 \\
23.10 \\
16.00 \\
23.10\end{array}$ & 14.40 & 24.00 \\
\hline
\end{tabular}

* All concentrations are percent by weight (g solute/loo g solution)

Sour-tartaric acid. Bitter-quinine sulfate, Sweet-sucrose, Salt sodium chloride sodium chloride are added to sucrose solutions (Beebe-Center et al, 1959; Pangborn, 1962). On the other hand, few studies have appeared that systematically explore the growth function for a single taste against one or another background provided by a second taste. Beebe-Center et al (1959) reported that in general the presence of sodium chloride reduced the sweetnesses of several concentrations of sugar, each changed in the same proportion. This equal suppression suggests that the growth rate of sucrose sweetness against salt backgrounds is probably unaffected, so that the primary effect of introducing sodium chloride is the reduction of sweetness by a constant percentage across the entire scale.

The present series of studies concern the sensory functions for sour, bitter, sweet. and salt when these tastes are judged in pure solutions and in solutions in which a second taste is present as a background.

\section{PROCEDURE}

Stimulus solutions were prepared on a percent-by-weight basis (grams solute/grams solution) from reagent grade chemicals (Merck), except sucrose (Domino brand cane sugar). The diluent was Cambridge tap water. Stimulus solutions were chosen at concentrations sufficiently above threshold so that the impurities in the tap water would have negligible effects upon the stimuli. Table $]$ gives the concentrations.

Sensory intensity was measured by two matching procedures: number matching (magnitude estimation) and noise matching. For the noise matches the Os were given control of a sone potentiometer (Poulton \& Stevens, 1955), and they 
Tabls.

Parameters of the Power Lav for Sour: $S=\mathrm{kC}^{\mathrm{a}}$

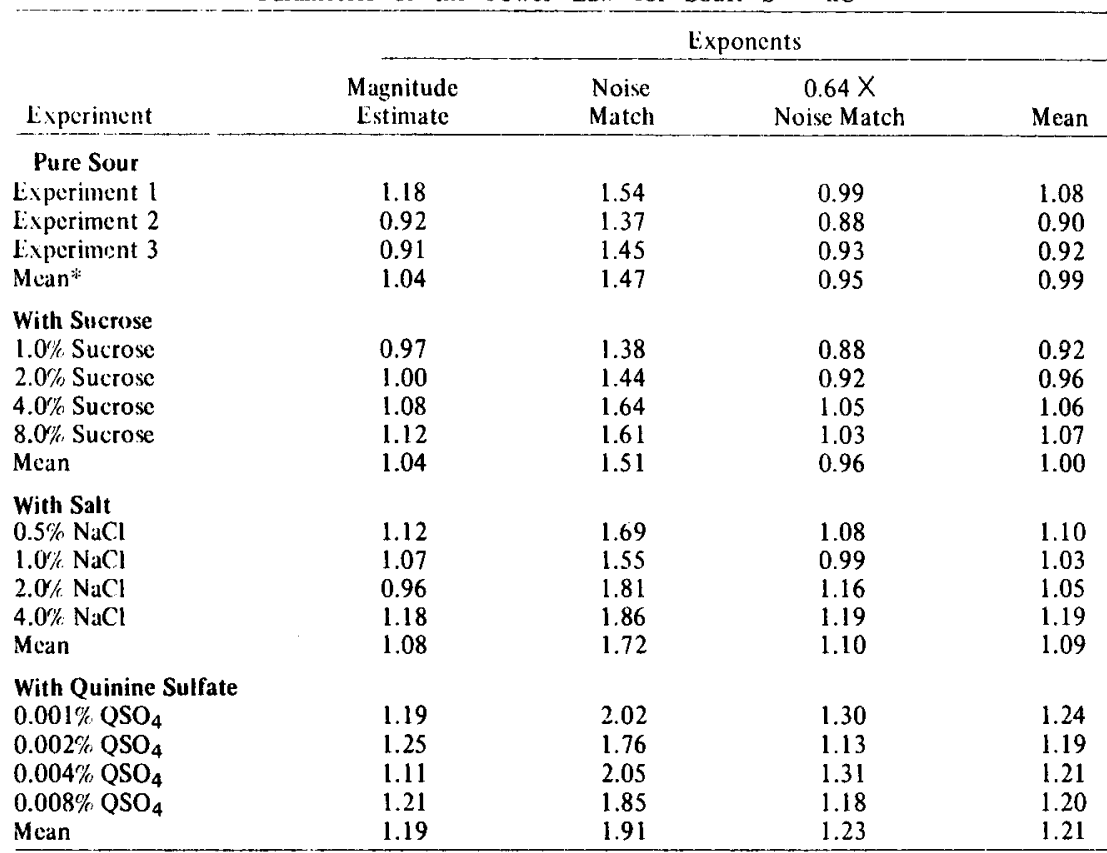

* Experiment 1 weighted twice

Table 3

A. Parameters of the Power Law for Bitter: $S=\mathbf{k C}^{\mathbf{a}}$

\begin{tabular}{|c|c|c|c|c|}
\hline \multirow[b]{2}{*}{ Lxperiment } & \multicolumn{4}{|c|}{ Exponents } \\
\hline & $\begin{array}{c}\text { Magnitude } \\
\text { Estimate }\end{array}$ & $\begin{array}{l}\text { Noise } \\
\text { Match }\end{array}$ & $\begin{array}{c}0.64 \times \\
\text { Noise Match }\end{array}$ & Mean \\
\hline $\begin{array}{l}\text { Pure Bitter } \\
\text { lixperiment } 1 \\
\text { lixperiment } 2 \\
\text { Experiment } 3 \\
\text { Mean* }\end{array}$ & $\begin{array}{l}0.98 \\
0.54 \\
0.62 \\
0.75\end{array}$ & $\begin{array}{l}1.49 \\
0.82 \\
0.97 \\
1.15\end{array}$ & $\begin{array}{l}0.95 \\
0.52 \\
0.62 \\
0.73\end{array}$ & $\begin{array}{l}0.97 \\
0.53 \\
0.62 \\
0.74\end{array}$ \\
\hline $\begin{array}{l}\text { With Salt } \\
0.5 \% \mathrm{NaCl} \\
1.0 \% \mathrm{NaCl} \\
2.0 \% \mathrm{NaCl} \\
4.0 \% \mathrm{NaCl} \\
\text { Mean }\end{array}$ & $\begin{array}{l}1.03 \\
1.12 \\
1.01 \\
1.12 \\
1.07\end{array}$ & $\begin{array}{l}1.78 \\
1.81 \\
1.69 \\
1.62 \\
1.72\end{array}$ & $\begin{array}{l}1.14 \\
1.16 \\
1.08 \\
1.04 \\
1.10\end{array}$ & $\begin{array}{l}1.08 \\
1.14 \\
1.05 \\
1.08 \\
1.08\end{array}$ \\
\hline $\begin{array}{l}\text { With Acid** } \\
0.02 \% \text { Acid } \\
0.04 \% \text { Acid } \\
0.08 \% \text { Acid } \\
0.15 \% \text { Acid } \\
\text { Mean }\end{array}$ & $\begin{array}{l}0.86 \\
1.34 \\
1.28 \\
0.94 \\
1.08\end{array}$ & $\begin{array}{l}1.86 \\
1.87 \\
1.96 \\
1.57 \\
1.81\end{array}$ & $\begin{array}{l}1.19 \\
1.19 \\
1.25 \\
1.00 \\
1.16\end{array}$ & $\begin{array}{l}1.01 \\
1.27 \\
1.27 \\
0.97 \\
1.12\end{array}$ \\
\hline $\begin{array}{l}\text { With Sucrose } \\
1.0 \% \text { Sucrose } \\
2.0 \% \text { Sucrose } \\
4.0 \% \text { Sucrose } \\
8.0 \% \text { Sucrose } \\
\text { Mean }\end{array}$ & $\begin{array}{l}1.01 \\
1.16 \\
1.17 \\
1.30 \\
1.16\end{array}$ & $\begin{array}{l}1.82 \\
1.90 \\
2.17 \\
2.07 \\
1.99\end{array}$ & $\begin{array}{l}1.16 \\
1.22 \\
1.39 \\
1.32 \\
1.27\end{array}$ & $\begin{array}{l}1.08 \\
1.19 \\
1.27 \\
1.31 \\
1.21\end{array}$ \\
\hline
\end{tabular}

B. Parameters of the Power Law for Bitter: $S=k\left(C+C_{0}\right)^{a}$

\begin{tabular}{lcc} 
& Experiment 2 & Experiment 3 \\
\hline Magnitude Estimation Exponent & 0.94 & 1.05 \\
Predicted Exponent & 0.78 & 1.03 \\
Mcan Lxponent & 0.86 & 1.04 \\
Co-Magnitude Lstimate & +0.015 & +0.014 \\
Co-Noise Match & +0.009 & +0.013 \\
\hline
\end{tabular}

* Experiment I weighted twice

** Tartaric acid

adjusted the loudness of a band of white noise $(500$ to $5,000 \mathrm{~Hz})$ to match taste intensity. They were given the following written instructions: "In front of you is a series of solutions in paper cups. Your task is to tell how sweet they seem by assigning numbers to them. Call the first stimulus any number that seems to you appropriate. Then assign successive numbers in such a way that they reflect your subjective impression. For example, if a solution seems 20 times as sweet, assign a number 20 times as large. If it seems one-tenth as sweet, assign a number one-tenth as large, and so forth. Use fractions, whole numbers, or decimals, but make each successive assignment proportional to the sweetness as you perceive it. In the second portion of the experiment you will match noise to sweetness. If the sweetness seems 20 times as intense, make the noise 20 times as loud. If it seems one-tenth as sweet, make the noise one-tenth as loud, and so forth. Make each loudness proportional to the sweetness as you perceive it." When Os judged one of the two tastes in the mixed solutions they were given the following additional instructions: "The solutions are made from pairs of chemicals, so you may perceive two tastes. Ignore the second taste, and judge only the sweetness as you perceive it." The italicized words were changed when other tastes were judged.

The geometric means and the standard deviations of both the number and noise matches were obtained from the raw data by a computer program known as PSYCHOFIT (Panek \& Stevens, 1965). The program provided an estimate of the exponent $n$ and the intercept $k$ of the simple power function $S=k I^{\mathrm{n}}$. Interest was focused only on the exponent because no common stimulus was present in the various experiments that could be used to relate their intercepts. The data are plotted in $\log -\log$ coordinates, and the highest concentration of each function has been arbitrarily assigned a magnitude estimate of 100 or a noise match of $95 \mathrm{~dB}$ (re $0.0002 \mathrm{dyne} / \mathrm{cm}^{2}$ ). This normalization was done in order to facilitate comparisons among the various functions.

\section{RESULTS}

A total of 137 taste functions were obtained, 69 from number matching and 68 from noise matching. Virtually all were approximately straight lines in $\log \log$ coordinates, strongly suggesting that for this sipping procedure taste intensity conforms to the general power law governing the growth of sensory magnitude. The exponents for both number and loudness matches are presented in Tables 2-5. In addition, the loudness matches have been used as an independent estimate of the number-concentration relation through the following three equations: (1) number = pressure 0.64 (Stevens, 1966a), (2) pressure 
Table 4

Parameters of the Power Law for Sweet: $S=\mathbf{k C}^{\mathbf{a}}$

\begin{tabular}{|c|c|c|c|c|}
\hline \multirow[b]{2}{*}{ Experiment } & \multicolumn{4}{|c|}{ Exponents } \\
\hline & $\begin{array}{l}\text { Magnitude } \\
\text { Estimate }\end{array}$ & $\begin{array}{l}\text { Noise } \\
\text { Match }\end{array}$ & $\begin{array}{c}0.64 \times \\
\text { Noise Match }\end{array}$ & Mean \\
\hline \multicolumn{5}{|l|}{ Pure Sweet } \\
\hline Experiment 1 & 1.45 & 2.04 & 1.31 & 1.38 \\
\hline Experiment 2 & 1.41 & 1.74 & 1.11 & 1.27 \\
\hline Experiment 3 & 1.66 & 2.88 & 1.84 & 1.75 \\
\hline Mean* & 1.49 & 2.13 & 1.36 & 1.43 \\
\hline \multicolumn{5}{|l|}{ With Salt } \\
\hline $0.5 \% \mathrm{NaCl}$ & 1.42 & 1.92 & 1.23 & 1.32 \\
\hline $1.0 \% \mathrm{NaCl}$ & 1.21 & 1.95 & 1.25 & 1.23 \\
\hline $2.0 \% \mathrm{NaCl}$ & 1.27 & 1.98 & 1.27 & 1.27 \\
\hline $4.0 \% \mathrm{NaCl}$ & 1.30 & 1.82 & 1.16 & 1.23 \\
\hline Mean & 1.30 & 1.92 & 1.23 & 1.26 \\
\hline \multicolumn{5}{|l|}{ With Acid** } \\
\hline $0.02 \%$ Acid & 1.27 & 1.89 & 1.21 & 1.24 \\
\hline $0.04 \%$ Acid & 1.28 & 1.99 & 1.27 & 1.28 \\
\hline $0.08 \%$ Acid & 1.36 & 1.95 & 1.25 & 1.30 \\
\hline $0.15 \%$ Acid & 1.32 & 2.08 & 1.33 & 1.33 \\
\hline Mean & 1.31 & 1.98 & 1.26 & 1.29 \\
\hline \multicolumn{5}{|c|}{ With Quinine Sulfate } \\
\hline $0.001 \% \mathrm{QSO}_{4}$ & 1.63 & 2.13 & 1.36 & 1.49 \\
\hline $0.002 \% \mathrm{QSO}_{4}$ & 1.53 & 2.21 & 1.41 & 1.47 \\
\hline $0.004 \% \mathrm{QSO}_{4}$ & 1.53 & 2.24 & 1.43 & 1.48 \\
\hline $0.008 \% \mathrm{QSO}_{4}$ & 1.76 & 2.24 & 1.43 & 1.59 \\
\hline Mean & 1.61 & 2.20 & 1.41 & 1.51 \\
\hline
\end{tabular}

*Experiment 1 weighted twice; ** Tartaric acid;

$=$ concentration $^{\mathrm{A}}$ (Tables 2-5), and (3) number $=$ concentration $0.64 \times \mathrm{A}$ (Eqs. 1 and 2).

Intensity functions for the four primary tastes appear in Figs. 1-4. Each of the four tastes was judged in at least three experiments. Sodium chloride (salt) was judged in six experiments with number matches and in five with noise matches. The functions for Experiment 1 of each of the four primary tastes (and Experiment 2 for salt) are based on 30 judgments per stimulus, three from each of $10 \mathrm{Os}$. The remaining functions represent 20 judgments per stimulus, two from each of 10 Os. The tastes group into two with high exponents (salt, sweet) and two with low exponents (sour, bitter). The lowest concentrations of quinine sulfate (Fig. 2, Experiments 2 and 3) flatten the bitter function and reduce its exponent (Table 3). This may have resulted from a residual amount of bitter in the mouth that produced a constant level of background bitterness. When the function was corrected by an additive constant (Table 3B), the exponent for bitter rose to around 1.0 .

Figure 5 presents a sample of the taste functions for sour judged against four levels of quinine sulfate. Across an 8:1 range of background level, the growth of sensory intensity is virtually unaffected. The two sets of functions (Figs. 1-4. Fig. 5) suggest that $O$ c can perceive and attend to a given taste in a mixture and that under the constant background provided by a lines suggest power functions. second taste, the dynamics of intensity growth for a given taste are relatively unaffected. The average amount of change of the exponent that occurs in taste mixtures is given in Table 6. The percentage change in the exponent from the pure taste to the mixture was always less than 25\%. This accords well with the variation of the exponent when a single taste is judged alone in several different experiments.

\section{Analogues to Glare and Masking}

The steepening of the loudness function under masking and of the brightness function under glare (Stevens, 1966b) do not appear to have analogues in the taste functions. The sipping procedure may not be sufficiently sensitive to pick out the changes in exponent that occur under different background levels. Because a large range of backgrounds was used $(8: 1$ intensity range), it appears likely that any steepening in the taste function due to the background would exhibit at most a minor effect with this tasting procedure. On the other hand, the invariance of the taste exponent under such varied types of backgrounds appears to be a first order effect and one that would not have been
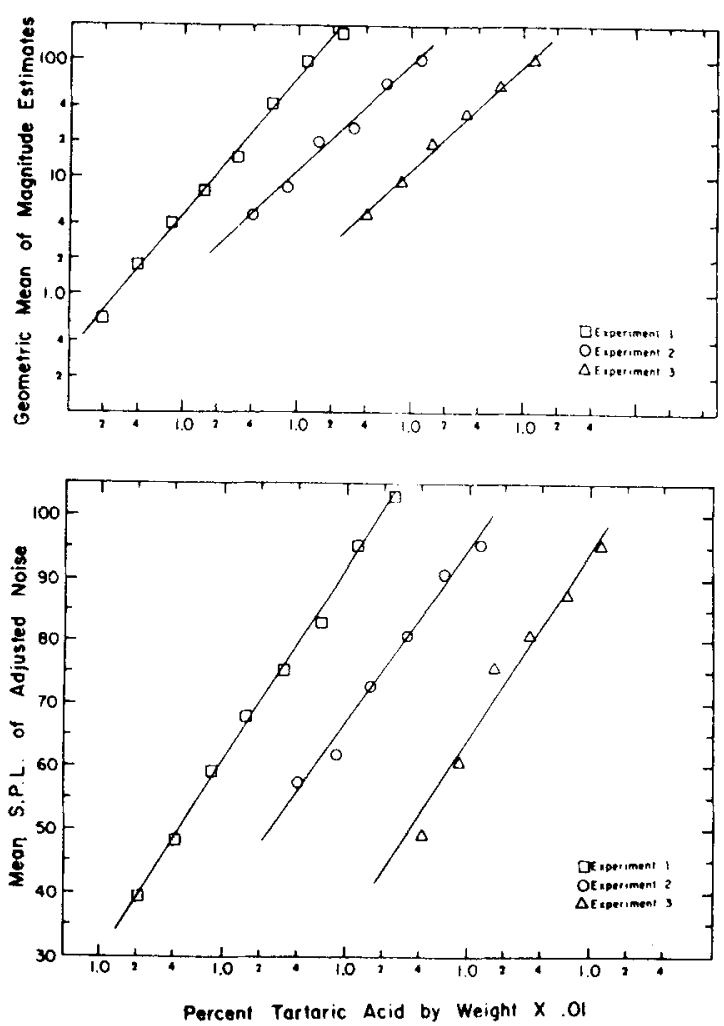

Fig. 1. Number and noise matches to the sourness of tartaric acid. The coordinates are log-log in each case, and straight 

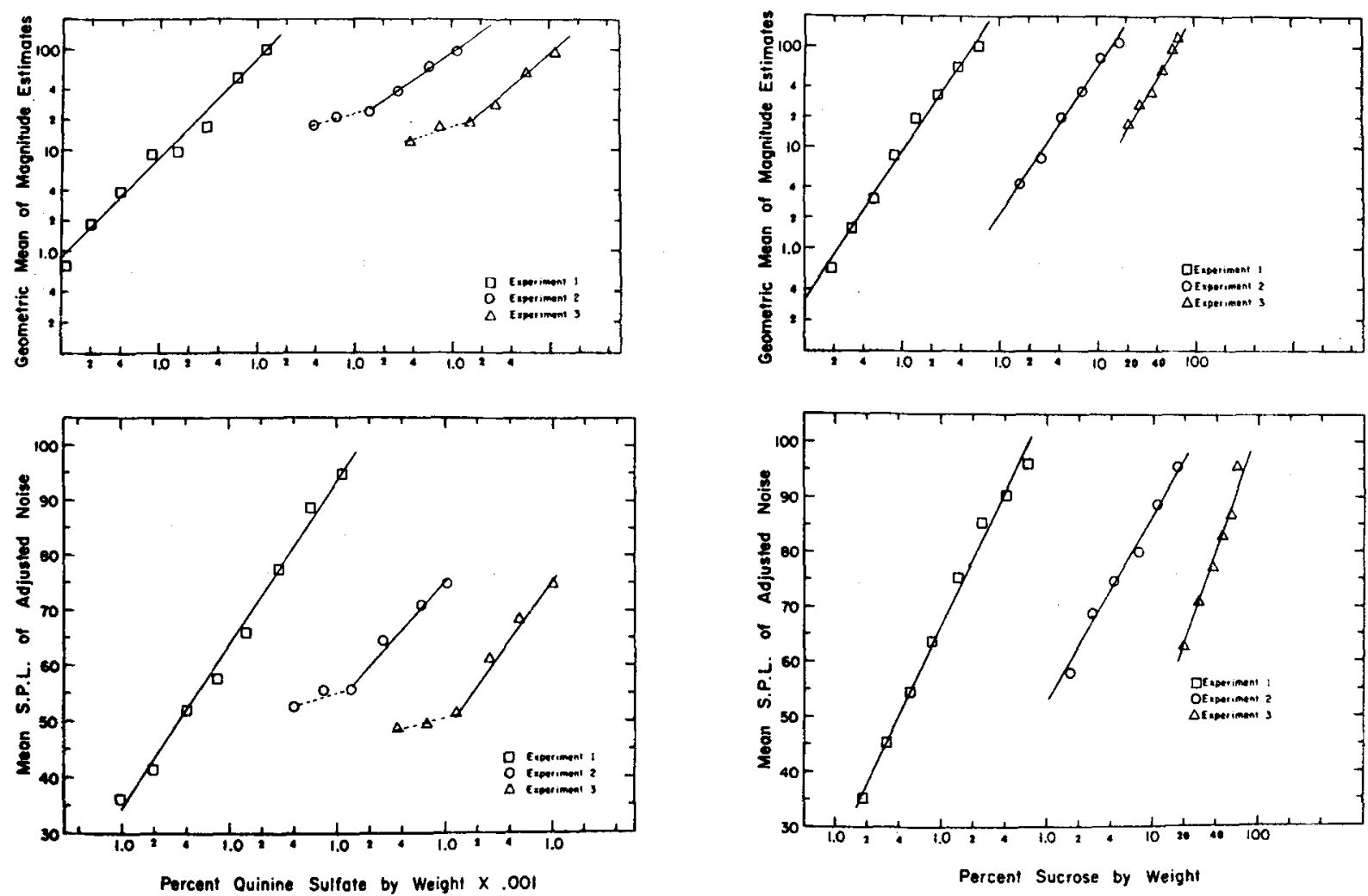

Fig. 2. Number and noise matches to the bitterness of quinine sulfate.
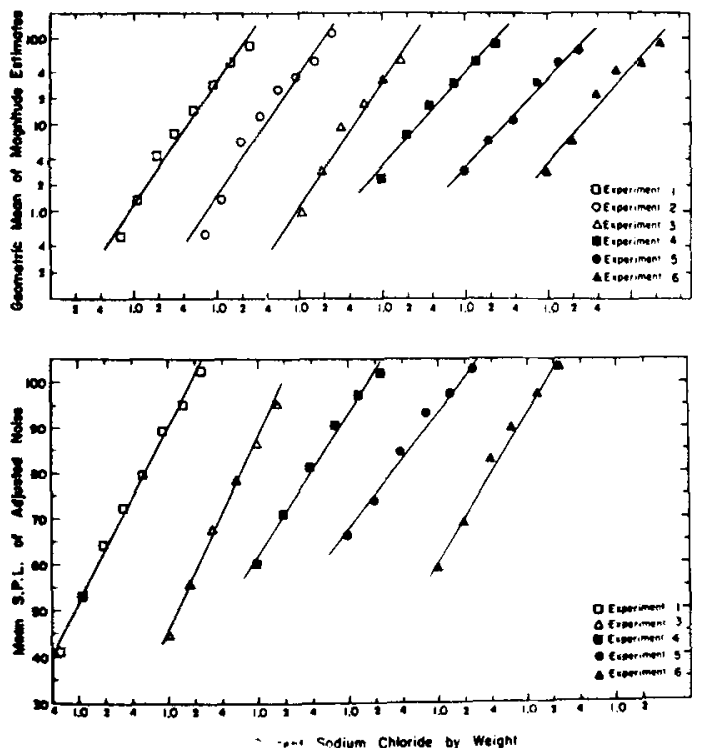

Fig. 4. Number and noise matches to the saltiness of sodium chloride.

expected if there was an analogy to the dynamics of loudness and brightness.

\section{Correspondence of Matching Procedures}

Because two modalities, number and loudness, were used as "sensory

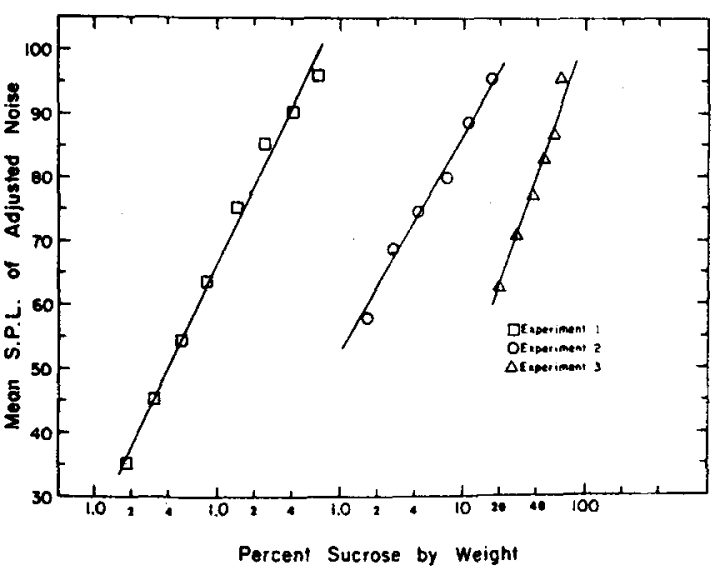

Fig. 3. Number and noise matches to the sweetness of sucros
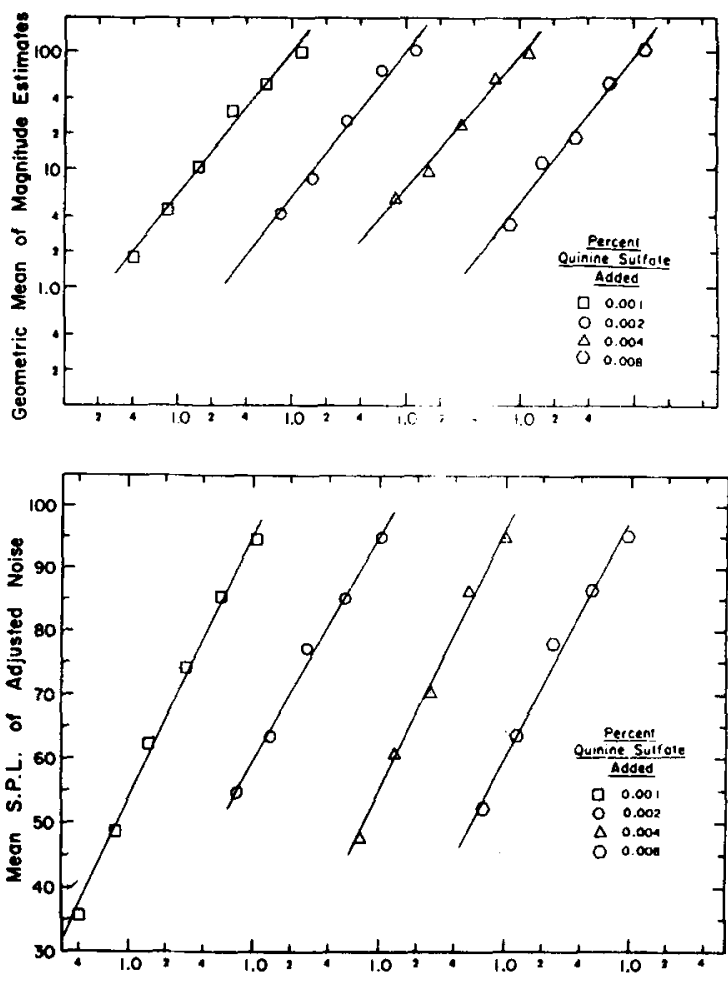

Percent Tortaric Acid by Weight $x$.0I

Fig. 5. Number and noise matches to the sourness of tartaric acid, judged against four background levels of quinine sulfate yardsticks," it is instructive to compare the simplest comparison is the ratio of th taste exponents obtained by each. The exponent for number vs concentration $t^{\prime}$ 
Table 5

Parameters of the Power Law for Saltiness: $S=\mathrm{kC}^{\mathrm{a}}$

\begin{tabular}{|c|c|c|c|c|}
\hline \multirow[b]{2}{*}{ Experiment } & \multicolumn{4}{|c|}{ Exponents } \\
\hline & $\begin{array}{c}\text { Magnitude } \\
\text { Estimate }\end{array}$ & $\begin{array}{l}\text { Noise } \\
\text { Match }\end{array}$ & $\begin{array}{c}0.64 \times \\
\text { Noise Match }\end{array}$ & Mean \\
\hline \multicolumn{5}{|l|}{ Pure Salt } \\
\hline Experiment 1 & 1.40 & 1.91 & 1.22 & 1.31 \\
\hline Experiment 2 & 1.43 & & & 1.43 \\
\hline Experiment 3 & 1.42 & 2.07 & 1.32 & 1.39 \\
\hline Experiment 4 & 1.09 & 1.52 & 0.97 & 1.03 \\
\hline Experiment 5 & 1.01 & 1.34 & 0.86 & 0.93 \\
\hline Experiment 6 & 1.10 & 1.64 & 1.05 & 1.07 \\
\hline Mean & 1.22 & 1.70 & 1.09 & 1.17 \\
\hline \multicolumn{5}{|l|}{ With Quinine Sulfatt } \\
\hline \multicolumn{5}{|l|}{ Series 1} \\
\hline $0.002 \% \mathrm{QSO}_{4}$ & 1.55 & 2.23 & 1.43 & 1.49 \\
\hline $0.004 \% \mathrm{QSO}_{4}$ & 1.62 & 2.13 & 1.36 & 1.48 \\
\hline $0.008 \% \mathrm{QSO}_{4}$ & 1.65 & 2.43 & 1.56 & 1.60 \\
\hline Mean & 1.60 & 2.26 & 1.45 & 1.52 \\
\hline \multicolumn{5}{|l|}{ Series 2} \\
\hline $0.004 \% \mathrm{QSO}_{4}$ & 1.61 & 2.12 & 1.36 & 1.48 \\
\hline $0.008 \% \mathrm{QSO}_{4}$ & 1.60 & 2.32 & 1.48 & 1.54 \\
\hline $0.015 \% \mathrm{QSO}_{4}$ & 1.44 & 2.02 & 1.29 & 1.36 \\
\hline Mean & 1.55 & 2.15 & 1.38 & 1.46 \\
\hline Girand Mean-QSO 4 & 1.57 & 2.20 & 1.40 & 1.49 \\
\hline \multicolumn{5}{|l|}{ With Sucrose } \\
\hline \multicolumn{5}{|l|}{ Series 1} \\
\hline $1.0 \%$ Sucrose & 1.65 & 2.13 & 1.36 & 1.50 \\
\hline $2.0 \%$ Sucrose & 1.53 & 1.98 & 1.27 & 1.39 \\
\hline $4.0 \%$ Sucrose & i. 51 & 2.25 & 1.44 & 1.47 \\
\hline Mean & 1.56 & 2.12 & 1.36 & 1.45 \\
\hline \multicolumn{5}{|l|}{ Series 2} \\
\hline $4.0 \%$ Sucrose & 1.23 & 1.78 & 1.14 & 1.18 \\
\hline $8.0 \%$ Sucrose & 1.44 & 1.90 & 1.22 & 1.32 \\
\hline $15.0 \%$ Sucrose & 1.55 & 1.79 & 1.15 & 1.33 \\
\hline Mean & 1.40 & 1.82 & 1.16 & 1.27 \\
\hline Grand Mean & 1.48 & 1.98 & 1.26 & 1.36 \\
\hline \multicolumn{5}{|l|}{ With Acid } \\
\hline \multicolumn{5}{|l|}{ Series 1} \\
\hline $0.02 \%$ Acid & 1.61 & 2.21 & 1.41 & 1.51 \\
\hline $0.04 \%$ Acid & 1.58 & 2.16 & 1.38 & 1.48 \\
\hline $0.08 \%$ Acid & 1.42 & 2.22 & 1.42 & 1.42 \\
\hline Mean & 1.53 & 2.19 & 1.40 & 1.46 \\
\hline \multicolumn{5}{|l|}{ Series 2} \\
\hline $0.08 \%$ Acid & 1.24 & 1.61 & 1.03 & 1.13 \\
\hline $0.15 \%$ Acid & 1.60 & 2.00 & 1.28 & 1.43 \\
\hline $0.30 \%$ Acid & 1.58 & 1.81 & 1.16 & 1.35 \\
\hline Mean & 1.45 & 1.79 & 1.15 & 1.30 \\
\hline Grand Mean & 1.49 & 1.98 & 1.27 & 1.38 \\
\hline
\end{tabular}

* Tartoric acid

Note-Experiment 2 on the saltiness of sodiun chloride tas run only as a magnirude estimation experiment.

the exponent of pressure vs concentration. Stevens (1969a) has published an independent analysis of the 68 pairs of taste exponents and presents a histogram of their distribution. The geometric mean of the 68 ratios came to 0.676 , which provides, incidentally, a rather firm estimate of the exponent relating loudness to pressure. The standard deviation of the ratio turned out to be 0.51 decilog, or about $12.5 \%$. This measure of the scatter around the mean ratio suggests that to within an SD of $12.5 \%$ the two procedures concur in their estimates of the exponent for taste intensity.
Table 6

A. Representative Exponents for Simple and Complex Tastes

Quality of the Second Taste in Solution

\begin{tabular}{lllll} 
& Sour & Bitter & Sweet & Salt \\
\hline Taste Judged & & & \\
Sour & 1.00 & 1.21 & 1.00 & 1.08 \\
Bitter & 1.12 & 0.97 & 1.21 & 1.08 \\
Sweet & 1.29 & $\overline{1.51}$ & 1.43 & 1.26 \\
Salt & 1.37 & 1.48 & $\overline{1.36}$ & 1.37
\end{tabular}

B. Percentage Change in the Size of the Exponent When Two Tastes Interact

\begin{tabular}{lrrrr} 
& \multicolumn{3}{c}{$\begin{array}{c}\text { Quajity of the Second } \\
\text { Taste in Solution }\end{array}$} \\
\hline & Sour & Bitter & Sweet & Salt \\
\hline Taste Judged & & & \\
Sour & $0 \%$ & $+21 \%$ & $0 \%$ & $+8 \%$ \\
Bitter & $+15 \%$ & $0 \% \%$ & $+24 \%$ & $+11 \%$ \\
Sweet & $-10 \%$ & $+6 \%$ & $0 \%$ & $12 \%$ \\
Salt & $0 \%$ & $+4 \%$ & $0 \%$ & $0 \%$ \\
\hline
\end{tabular}

intensity and taste preference. Perceptual and Motor Skills, 1969, 28, 735-740.

MCBURNFY, D. H. A psychophysical study of gustatory adaptation. Unpublished doctoral thesis, Brown University, 1965.

MEISELMAN, H. L. Adaptation and cross-adaptation of the four gustatory qualities. Perception \& Psychophysics, 1968 , 4, 368-372.

MOSKOWITZ, H. R. Ratio scales of sugar sweetness. Perception \& Psychophysics, 1970a $7,315-320$.

MOSKOWITZ, H. R. Sweeiness and intensity of artificial sweeteners. Perception \& Psychophysics, 1970b, 8, 40-42.

PANIK, D. W., \& STEVENS, J. ( . Psychofit, a computer program for the treatment of psychophysical data. Laboratory of Psychophysics, Harvard University, 1965. PPR 315.

PANGBORN, R. M. Taste interrelationships lood Rescarch. 1960, 25, 245-256.

PANGBORN, R. M. Taste interrelationships. II. Suprathreshold solutions of sucrose and citric acid. Journal of liood Science, 1961, 26 , 648-655.

PANGBOR N. R. M. Tastc interrelationships. H1. Suprathreshold solutions of sucrose and sodium chloride. Journal of lood Science. 1962. 27. 495-500.

PIAIIMANN, C.. BARTOSHUK, L., \& MCBURNEY, D. Taste psychophysics. In Handbook of sensory physiology. Springer-Verlag, 1970. In press.

POULTON, l. (., \& STEVENS, S. S. On the halving and doubling of the loudness of white noisc. Journal of the Acoustical Society of A merica, 1955, 27, 329-331.

Sl\%VI:NS, S. S. On the brightness of lights and the loudness of sounds. Science, 1953, 118 576.

STl:VLNS, S. S. The psychophysies of sensory function. American Scientist, 1960, 48 $226 \cdot 253$

STIVINS, S. S. Matching functions between loudness and ten other continua. Perception \& Psychophysics. 1966a, 1, 5-8.

STIVVI:NS, S. S. Power group transformations under glare, masking, and recruitment. Journal of the Acoustical Soctety of America, 1966h. 39. $725-735$. 
STEVIENS, S. S. On predicting cxponents for cross-modality matches. Perception \& Psychophysics, 1969a, 6, 251-256.

STEVENS, S. S. Sensory scales of taste intensity. Perception \& Psychophysics. 1969b, 6 , 302-308.

STEVENS, S. S., \& STFVENS, J. C. The dynamics of visual brightness. Unpublished monograph, Harvard University, Laboratory of

Psychophysics, 1960, PPR 246.

\section{NOTE}

1. Meiselman, H. L. Iiffect of procedure and adaptation level in gustatory psychophysical functions. Unpublished manuscript.

(Accepted for publication April 24, 1970.) 